\title{
PENGARUH JURI, PRESTASI SEBELUMNYA DAN TINGKAT INSTITUSI TERHADAP PENILAIAN DALAM LOMBA WEB-SITE LINGKUP KEMENTRIAN PERTANIAN
}

\author{
Edi Abdurachman \\ Jurusan Statistika, Fakultas Sains and Technology, Bina Nusantara University \\ Jln. K.H. Syahdan No. 9, Kemanggisan, Palmerah, Jakarta 11480 \\ edia@binus.edu
}

\begin{abstract}
In promoting the use of Information and Communication Technology (ICT) in order to improve efficiency and effectiveness of government service institutions, the Government of Indonesia issued Presidential Instruction No. 3 of 2003 on e-Government. The directive requested that all government institutions in Indonesia should take advantage of ICT to improve public services. In line with this, the Ministry of Agriculture has launched several efforts to support the implementation of Presidential Instruction. One of these efforts is the implementation of the Web Site Competition between Work units under the Ministry. The contest has been held since 2004. The participants were grouped into three categories: 1. Directorate General / Agency 2. Provincial Agricultural Office 3. District Agriculture Office. To carry out the website competition, the Ministry of Agriculture has appointed a five person jury. To evaluate whether there are significant differences between the judges in scoring on the website which was considered and the factors that may affect the assessment, some analysis has been done. The variables included in the analysis was judge scores, level of institution, previous achievements in the competition, the location of both institutions in Java and outside Java. The statistical methods used in the analysis are Multiple Linear Regression and Variance Analysis. The analysis uses data from the Ministry of Agriculture Web Site Competition 2008-2010.
\end{abstract}

Keywords: assessment, judges, website competition, Ministry of Agriculture

\begin{abstract}
ABSTRAK
Dalam mempromosikan penggunaan Teknologi Informasi dan Komunikasi (TIK) dalam rangka meningkatkan efisiensi dan efektivitas layanan insitusi pemerintah, Pemerintah Indonesia telah mengeluarkan Instruksi Presiden Nomor 3 Tahun 2003 tentang e-Government. Instruksi tersebut meminta agar semua lembaga pemerintahan di Indonesia harus memanfaatkan TIK untuk meningkatkan pelayanan publik. Sejalan dengan ini, Kermenterian Pertanian telah melakukan beberapa upaya untuk mendukung pelaksanaan Inpres tersebut. Salah satu upaya tersebut adalah pelaksanaan Lomba Situs Web di antara unit kerja lingkup Pertanian. Kontes telah dilakukan sejak tahun 2004. Para peserta dikelompokkan menjadi tiga kategori yaitu 1. Direktorat Jenderal / Badan; 2. Dinas Pertanian Provinsi 3. Dinas Pertanian Kabupaten/Kota. Untuk melaksanakan lomba situs web, Kementerian Pertanian telah menunjuk 5 orang juri. Untuk mengevaluasi apakah ada perbedaan yang signifikan antara juri dalam memberikan skor pada situs web yang dinilai dan faktor-faktor saja yang mungkin berpengaruh dalam penilaian tersebut, beberapa analisis telah dilakukan. Variabel yang dimasukkan dalam analisis adalah skor Juri, Tingkat lembaga, Prestasi sebelumnya dalam lomba, lokasi lembaga baik di Jawa maupun di luar Jawa. Metode statistik yang digunakan dalam analisis adalah Regresi Linier Berganda, dan Analisis Varians. Analisis menggunakan data dari Lomba Situs Web Kementerian Pertanian tahun 20082010.
\end{abstract}

Kata kunci: penilaian, juri, lomba situs web, Kementrian Pertanian 


\section{PENDAHULUAN}

Dalam mempromosikan penggunaan Teknologi Informasi dan Komunikasi (TIK) untuk meningkatkan efisiensi dan efektivitas layanan pemerintah, Pemerintah Indonesia telah mengeluarkan Instruksi Presiden Nomor 3 Tahun 2003. Instruksi tersebut meminta agar semua lembaga pemerintah di Indonesia harus memanfaatkan TIK untuk meningkatkan pelayanan kepada publik. Sejalan dengan ini, Kermenterian Pertanian Indonesia (Kementerian Pertanian) juga telah melakukan beberapa upaya ke arah ini, yang salah satunya adalah Lomba Web di antara unit-unit dalam Kementerian Pertanian. Kontes telah dilakukan sejak tahun 2004. Para peserta dikelompokkan menjadi tiga kategori: 1. Direktorat Jenderal / Badan; 2. Dinas Pertanian Provinsi 3. Dinas Pertanian Kabupaten/Kota. Untuk melaksanakan kontes-situs web, Kementerian Pertanian telah menunjuk 5 orang juri, yang dibantu oleh Tim Sekretariat.

Tujuan dari penelitian ini adalah: 1. Untuk mengetahui apakah para juri dalam menilai website telah dilakukan secara objektif atau dengan perkataan lain apakah ada perbedaan yang signifikan antar juri dalam memberikan penilaian; 2. Untuk mengidentifikasi faktor-faktor apa saja yang berpengaruh signifikan terhadap hasil penilaian juri.

\section{TinJAUAN PUSTAKa}

\section{E-Government}

E-government, berdasarkan definisi Bank Dunia adalah penggunaan teknologi informasi oleh kantor-kantor pemerintah untuk pelayanan yang lebih baik kepada masyarakat, dunia bisnis serta untuk memfasilitasi kerjasama antar lembaga pemerintah. Penggunaan E-government diharapkan mampu memberdayakan masyarakat melalui akses publik terhadap sumber daya informasi yang tersedia (Pusat Sumberdaya Geologi, 2003). E-government adalah upaya untuk mengembangkan penyelenggaraan kepemerintahan yang berbasis elektronik dalam rangka meningkatkan kualitas layanan publik secara efektif dan efisien.

Berdasarkan Instruksi Presiden Nomor 3 Tahun 2003, pencapaian tujuan strategis egovernment perlu dilaksanakan melalui 6 (enam) strategi yang berkaitan erat, yaitu:

1. Mengembangkan sistem pelayanan yang andal dan terpercaya, serta terjangkau oleh masyarakat luas.

2. Menata sistem manajemen dan proses kerja pemerintah dan pemerintah daerah otonom secara holistik.

3. Memanfaatkan teknologi informasi secara optimal.

4. Meningkatkan peran serta dunia usaha dan mengembangkan industry telekomunikasi dan teknologi informasi.

5. Mengembangkan kapasitas SDM baik pada pemerintah maupun pemerintah daerah otonom, disertai dengan meningkatkan e-literacy masyarakat.

6. Melaksanakan pengembangan secara sistematik melalui tahapan-tahapan yang realistik dan terukur. Berdasarkan sifat transaksi informasi dan pelayanan publik yang disediakan oleh pemerintah melalui jaringan informasi, pengembangan egovernment dapat dilaksanakan melalui 4 (empat) tahapan berikut:

- Tingkat 1 - Persiapan yang meliputi:

- Pembuatan situs informasi di setiap lembaga;

- Penyiapan SDM;

- Penyiapan sarana akses yang mudah misalnya menyediakan sarana Multipurpose Community Center, Warnet, SME-Center, dll;

- Sosialisasi situs informasi baik untuk internal maupun untuk publik. 
- Tahap 2 - Pematangan yang meliputi:

- Pembuatan situs informasi publik interaktif;

- Pembuatan antar muka keterhubungan dengan lembaga lain;

- Tahap 3 - Pemantapan yang meliputi:

- Pembuatan situs transaksi pelayanan publik;

- Pembuatan interoperabilitas aplikasi maupun data dengan lembaga lain.

- Tahap 4 - Pemanfaatan yang meliputi:

- Pembuatan aplikasi untuk pelayanan yang bersifat G2G, G2B dan G2C yang terintegrasi.

\section{Membangun Situs Web Yang Baik}

Pembangunan situs web merupakan salah satu strategi (strategi 6) Kebijakan dan Strategi Nasional Pengembangan e-Government, yaitu melaksanakan pengembangan secara sistematik melalui tahapan yang realistik dan terukur. Mengacu kepada Kementerian Komunikasi dan Informasi, terdapat lima masalah yang perlu diperhatikan dalam membangun dan meng-implementasikan strategi publikasi melalui media online (Kementerian Komunikasi dan Informasi, 2003a), yaitu :

- kegunaan - untuk keperluan apa suatu situs web pemerintah daerah dibuat?

- tanggung jawab - siapa pemilik situs web dan siapa yang bertanggung jawab ?

- manajemen situs - bagaimana cara pemberian dan permintaan layanan ?

- isi - bagaimana materi disediakan, dipelihara, dan dipresentasikan dalam bentuk media online ?

- pemutakhiran dan pemeliharaan - bagaimana cara melakukan pemantauan.

Salah satu komitmen kunci dari pemerintah adalah memberikan jasa layanan masyarakat yang responsif di dalam memenuhi kebutuhan semua kelompok yang berbeda di masyarakat

\section{Pengembangan Situs Web Pemerintah}

Situs web pemerintah dapat dikatakan sebagai salah satu media informasi dan komunikasi dari suatu lembaga pemerintah kepada masyarakat mengenai segala sesuatu yang berhubungan dengan lembaga pemerintah bersangkutan. Pembuatan situs web pemerintah mempunyai sasaran agar masyarakat Indonesia dapat dengan mudah memperoleh akses kepada informasi dan layanan lembaga pemerintah. Situs web pemerintah dibuat sesuai dengan keinginan pemerintah dalam pemberian pelayanan kepada masyarakat yaitu :

1. Perolehan informasi secara mudah, benar, adil, dan luas cakupan;

2. Penyebarluasan informasi melalui media elektronik yang meliputi :

- semua bahan yang telah diterbitkan atau bahan-bahan yang telah berada di luar perlindungan hak cipta (boleh diketahui oleh umum);

- semua informasi yang dibuat dan dikumpulkan sesuai undang-undang (tunduk kepada pertimbangan-pertimbangan kepekaan komersial dan rahasia pribadi);

- semua dokumen yang diperlukan bagi kepentingan masyarakat.

Situs web pemerintah harus berfokus pada:

a. Penyediaan informasi dan layanan publik yang diinginkan oleh masyarakat dengan secara terus menerus ber-evolusi di dalam pemberian informasi dan layanan publiknya;

b. Pencapaian aksesibilitas dan kegunaan universal;

c. Pemberian layanan interaktif;

d. Perlakuan yang tidak diskriminasi bagi pengunjung, artinya situs web pemerintah dapat dibuka tanpa membedakan fasilitas dan kemampuan komputer yang dimiliki oleh pengunjung.

Salah satu komitmen kunci dari pemerintah adalah memberikan jasa layanan masyarakat yang responsif di dalam memenuhi kebutuhan semua kelompok yang berbeda di masyarakat. 


\section{Standarisasi Pengembangan Situs Web}

Unsur terpenting dari sebuah tampilan yang efektif situs web di internet adalah isi dan disain yang baik serta menarik (Kementerian Komunikasi dan Informasi, 2003b).

Isi situs web pemerintah merupakan sejumlah informasi yang akan disampaikan oleh suatu lembaga pemerintah kepada masyarakat. Situs web pemerintah merupakan salah satu media komunikasi milik pemerintah, oleh sebab itu informasi yang disampaikan bukan hanya informasi atas keinginan lembaga pemerintah saja (komunikasi satu arah), tetapi juga harus memperhatikan sejumlah informasi yang diperlukan oleh masyarakat (komunikasi dua arah). Isi minimal situs web pemerintah berbeda antara situs web lembaga pemerintah pusat dan situs web lembaga pemerintah daerah.

Isi mimal situs web lembaga pemerintah pusat adalah:

1. Organisasi lembaga pemerintah pusat

Menjelaskan visi dan misi, Tugas Pokok dan Fungsi (Tupoksi), struktur organisasi, Rencana Strategi (Renstra), nama pejabat sampai tingkat eselon 2 (jika dimungkinkan mencantumkan alamat e-mailnya), biodata menteri dan pejabat eselon 1, data (alamat kantor, nomor telepon/fax, alamat email) lembaga pemerintah.

2. Berita

Pada setiap situs web lembaga pemerintah pusat harus menyajikan berita dari lingkungannya. Berita yang disajikan bisa diperoleh dari internal lembaga pemerintah pusat atau dari mediamassa (pusat dan daerah).

3. Peraturan/Kebijakan

Memuat dan menjelaskan semua undang-undang/kebijakan beserta turunannya yang telah dikeluarkan oleh lembaga pemerintah pusat bersangkutan. Situs web lembaga pemerintah pusat merupakan salah satu media untuk mensosialisasikan undang-undang/kebijakan yang telah dikeluarkan kepada masyarakat.

4. Penjelasan Direktorat Jenderal/Deputi

Mengingat tidak semua masyarakat mengetahui secara tepat organisasi yang terdapat di suatu lembaga pemerintah pusat, maka pada situs web lembaga pemerintah pusat sebaiknya terdapat penjelasan secara detil tentang Direktorat Jenderal atau Deputi yang terdapat di lingkungannya. Jika memungkinkan adanya link pada situs web masing-masing Direktorat Jenderal/Deputi.

Isi minimal pada setiap situs web pemerintah daerah adalah:

1. Selayang Pandang

Menjelaskan secara singkat tentang keberadaan Pemerintah Daerah bersangkutan (sejarah, motto daerah, lambang dan arti lambang, lokasi dalam bentuk peta, visi dan misi).

2. Pemerintahan Daerah

Menjelaskan struktur organisasi yang ada di Pemerintah Daerah bersangkutan (eksekutif, legislatif) beserta nama, alamat, telepon, e-mail dari pejabat daerah. Jika memungkinkan biodata dari Pimpinan Daerah ditampilkan agar masyarakat luas mengetahuinya.

3. Geografi

Menjelaskan antara lain tentang keadaan topografi, demografi, cuaca dan iklim, sosial dan ekonomi, budaya dari daerah bersangkutan. Semua data dalam bentuk numeris atau statistik harus mencantumkan nama instansi dari sumber datanya.

4. Peta Wilayah dan Sumberdaya

Menyajikan batas administrasi wilayah dalam bentuk peta wilayah (sebaiknya digunakan peta referensi yang dikeluarkan oleh Badan Koordinasi Survei dan Pemetaan Nasional - Bakosurtanal, atau instansi pemerintah lainnya yang mempunyai tugas pokok dan fungsi pembuat peta), dan juga sumberdaya yang dimiliki oleh daerah bersangkutan dalam bentuk peta sumberdaya (digunakan peta referensi yang dikeluarkan oleh instansi pemerintah yang mempunyai tugas pokok dan fungsi pembuat peta) yang dapat diguna-kan untuk keperluan para pengguna.

5. Peraturan/Kebijakan Daerah 
Menjelaskan Peraturan Daerah (Perda) yang telah dikeluarkan oleh Pemerintah Daerah bersangkutan. Melalui situs web pemerintah daerah inilah semua Perda yang telah dikeluarkan dapat disosialisasikan kepada masyarakat luas.

6. Berita

Berita dari lingkungan lembaga pemerintah daerah setempat, bukan diambil dari surat kabar lokal. Diharapkan berita situs web pemerintah daerah menjadi acuan atau referensi untuk berita yang diterbitkan oleh surat kabar lokal.

Selain enam isi minimal tersebut diatas, situs web pemerintah juga harus mampu melakukan interaksi dengan masyarakat melalui komunikasi dua arah antar pengelola situs web dan pengunjung melalui Forum Diskusi, saran pengunjung pada Buku Tamu. Homepage pada suatu situs web identik dengan sampul suatu buku yang dipublikasi. Suatu bentuk homepage yang menarik akan mempunyai kesan tersendiri bagi pengunjung situs web untuk ingin mengetahui lebih jauh tentang isi dari situs web bersangkutan. Suatu homepage dari situs web pemerintah daerah minimal menyangkut hal-hal sebagai berikut :

1. Nama Pemerintah Daerah;

2. Logo atau simbol Pemerintah Daerah;

3. Alamat kantor, nomor telepon dan fax, alamat e-mail Pemerintah Daerah;

4. Suatu gambar dalam bentuk citra (image) yang memberikan informasi tentang sesuatu yang menarik dari daerah bersangkutan (landmark), bisa berbentuk pemandangan, gedung monumental, atau produk unggulan;

5. Suatu teks kalimat yang berhubungan dengan keberadaan situs web pemerintah daerah (jargon);

6. Kontak e-mail (alamat e-mail Manajer Situs) untuk menyampaikan suatu permintaan atau keterangan;

7. Link dengan isi yang tersedia pada situs web pemerintah daerah;

8. Fasilitas pencarian.

Selain isi dari suatu situs web, hal yang perlu ditangani oleh pengelola situs web pemerintah daerah adalah disain situs web standar penyajian (visualisasi) yang meliputi homepage dan navigasi, bentuk standar teks dan tampilan grafis yang digunakan, HTML (Hyper Text Markup Language).

Ada banyak faktor sebagai bahan pertimbangan untuk menentukan baik buruknya kualitas sebuah website, dan setiap orang tentu memiliki pandangan yang berbeda-beda. Namun diantara sekian banyak tersebut, ada beberapa hal yang sudah umum dipakai acuan, yaitu :

1. Kecepatan download

Pengguna internet pada umumnya tidak betah menunggu. Mereka tidak suka berlama-lama hanya untuk menunggu munculnya informasi dari web yang diakses. Sedapat mungkin pengelola harus mengoptimalkan desain web agar tidak terlalu berat untuk diakses, sekalipun menggunakan koneksi dial-up. Kecepatan akses yang ideal sekitar 8 - 12 detik. Optimalkan kembali komponenkomponen web (image, HTML, JavaScript, CSS) jika belum mencapai angka tersebut.

2. Isi mudah dibaca

Sedapat mungkin janganlah menggunakan font yang terlalu kecil, dan warna yang kontras sehingga cepat membuat mata lelah. Buatlah pengunjung nyaman untuk membaca informasi yang disediakan, tanpa harus merubah setting font pada browser atau bahkan sampai merubah Brightness dan Contrast pada monitor.

3. Tata letak desain yang konsisten

Desain dari satu halaman ke halaman lain harus dibuat konsisten untuk memudahkan pengunjung menemukan content yang disediakan. Pengunjung akan merasa bingung jika menu yang diletakkan di halaman pertama dan kedua berubah-ubah posisinya. Buat pengunjung mudah beradaptasi, dengan desain ringan dan navigasi yang user friendly. 
Sebuah situs web pemerintah harus berfokus pada:

1. Penyediaan informasi dan layanan publik yang diinginkan oleh masyarakat dengan secara terus menerus ber-evolusi di dalam pemberian informasi dan layanan publiknya;

2. Pencapaian aksesibilitas dan kegunaan universal;

3. Pemberian layanan interaktif;

4. Perlakuan yang tidak diskriminasi bagi pengunjung, artinya situs web pemerintah dapat dibuka tanpa membedakan fasilitas dan kemampuan komputer yang dimiliki oleh pengunjung.

\section{Rating Situs Web Pemerintah}

Untuk mengetahui tingkat kemampuan, kehandalan, dan mutu suatu situs web pemerintah, Kementerian Komunikasi dan Informasi melakukan penilaian terhadap semua situs web pemerintah yang ada di Internet. Terdapat 11 (sebelas) parameter yang digunakan untuk penilaian situs web pemerintah yaitu :

1. kecepatan (speed);

2. homepage

3. isi (contents)

4. konteks

5. ukuran kualitas interaksi (usability)

6. kemudahan dibaca (readibility)

7. mobilitas data

8. ketepatan (accuracy)

9. layanan publik

10.hits

11.penggunaan platform

Berdasarkan 11 parameter yang telah ditentukan diatas, penilaian suatu situs web pemerintah di kelompokkan dalam 4 kriteria untuk dapat melakukan penentuan rating situs web pemerintah. Adapun 4 kriteria penilaian situs web pemerintah adalah:

1. Fungsi situs web;

2. Kualitas situs web;

3. Tampilan situs web;

4. Inovasi.

\section{Pelaksanaan e-Government di lingkup Kementrian Pertanian}

Pengembangan e-Government di Kementerian Pertanian diawali dengan pembangunan situs web Kementerian Pertanian. Pembangunan dan pengembangan Situs Web Kementerian Pertanian (http://www.deptan.go.id) telah dimulai sejak tahun 1996. Pusat Data dan Informasi Pertanian (Pusdatin) mengawali kegiatan tersebut dengan menyediakan beberapa menu yang menampilkan berbagai data dan informasi pertanian yang bersifat umum.

Pada tahun-tahun berikutnya pengembangan situs web dilakukan dengan melengkapi menu yang menampilkan informasi dengan kategori fungsi unit kerja eselon I lingkup Kementerian Pertanian. Selain itu sesuai dengan perkembangan teknologi informasi, situs web Kementerian Pertanian dikembangkan sebagai media komunikasi yang interaktif dalam penyebarluasan data dan informasi pertanian.

Selanjutnya, sebagai wujud komitmen terhadap pelayanan prima dalam hal penyediaan dan penyebarluasan data dan informasi kepada seluruh pengguna, sejak tahun 2002 telah dibentuk Pokja Pengelola Situs Web Kementerian Pertanian dan Tim Redaksi yang dikukuhkan dengan Keputusan Menteri Pertanian Nomor 508 dan 509 Kpts/Kp.150/9/2002. 
Melalui keberadaan Pokja dan Tim Redaksi yang beranggotakan para pengelola data dan informasi di seluruh unit kerja eselon II lingkup Kementerian Pertanian, kegiatan pengisian dan peremajaan data dan informasi menjadi lebih terkoordinasi. Selain itu, secara bertahap dibangun situs web Eselon I yang menyediakan informasi sesuai fungsinya masing-masing dalam bentuk tampilan situs web eselon II.

\section{Lomba Situs Web Lingkup Kementrian Pertanian}

Sebagai upaya untuk menjaga kesinambungan penyelenggaraan situs web Kementerian Pertanian, sejak tahun 2004 Pusdatin telah menyelenggarakan lomba situs web Eselon I lingkup Kementerian Pertanian. Tahun berikutnya lomba situs web diselenggarakan kembali, selain antar Eselon I Kementerian Pertanian juga antar Satuan Kerja Pemerintah Daerah (SKPD) lingkup pertanian provinsi dan SKPD lingkup pertanian kabupaten/kota.

Tujuan dari penyelenggaraan lomba situs web ini adalah memotivasi semua Eselon I lingkup Kementerian Pertanian, semua SKPD lingkup pertanian provinsi dan semua SKPD lingkup pertanian kabupaten/kota untuk mengkoordinasikan pengisian dan peremajaan data dan informasi yang ditampilkan; mendukung percepatan pelaksanaan e-Government; dan menyediakan pelayanan bagi masyarakat yang komunikatif, interaktif, informatif dan transaksional. Sasaran yang ingin dicapai adalah termotivasinya instansi pusat dan daerah untuk mengembangkan situs webnya; serta terpelihara dan diperbaharuinya data dan informasi pertanian pada situs web pusat dan daerah.

Untuk melaksanakan penilaian situs web, Kementrian Pertanian menunjuk 5 (lima) orang juri dari 5 (lima) instansi berbeda. Kriteria penilaian lomba situs web sebagian besar mengacu kepada parameter yang digunakan Kementerian Komunikasi dan Informasi dalam melakukan rating situs web pemerintah daerah. Kriteria yang digunakan adalah isi situs web; fitur situs web; layanan publik; kualitas situs web; dan inovasi pada situs web.

Dampak positif dari penyelenggaraan lomba situs web tersebut adalah semakin teraturnya peremajaan situs web masing-masing Eselon I dan situs web SKPD lingkup pertanian provinsi serta SKPD lingkup pertanian kabupaten/kota. Hal ini menjadikan content situs web Kementerian Pertanian juga semakin diperkaya dengan adanya link ke masing-masing web tersebut.

\section{METODE}

\section{Metode Pengumpulan Data}

Data yang digunakan pada penelitian ini diperoleh dari data lomba situs web tahun 2008 2010. Variabel-variabel yang digunakan adalah skor hasil penilaian para juri, level instansi (apakah pusat, provinsi, atau kabupaten), prestasi tahun sebelumnya (apakah masuk 3 besar atau tidak), dan lokasi instansi (apakah berada di Jawa atau Luar Jawa). Data yang akan dianalisis terdiri dari nilai rata-rata skor hasil penilaian tim juri untuk 12 situs web Eselon I, 10 situs web SKPD lingkup pertanian provinsi, dan 10 situs web lingkup pertanian kabupaten/kota dengan skala penilaian 1-100.

\section{Model Penelitian}

Penelitian ini bertujuan untuk mengetahui apakah para juri memberikan dalam memberikan nilai pada situs web yang dinilai independen satu sama lain dan untuk mengidentifikasi faktor-faktor apa saja yang berpengaruh signifikan terhadap hasil penilaian para juri. 
Untuk mengevaluasi apakah ada perbedaan yang signifikan antar juri dalam memberikan skor terhadap situs web yang dinilai, digunakan metode statistik Analysis of Variance (ANOVA). Hipotesis yang digunakan adalah:

$\mathrm{H}_{0}: \mu_{1}=\mu_{2}=\mu_{3}=\mu_{4}=\mu_{5}$

$\mathrm{H}_{1}$ : paling tidak satu $\mu_{\mathrm{i}} \neq \mu_{\mathrm{j}}$

Level of significance $(\alpha)$ yang digunakan dalam penelitian ini adalah 0,05 . Jika $F$ value $\geq F$ tabel maka tolak $\mathrm{H}_{0}$, tetapi jika $\mathrm{F}$ value $<\mathrm{F}$-tabel maka terima $\mathrm{H}_{0}$.

Keterangan:

$\mu_{1}=$ rata-rata hasil penilaian juri ke-1

$\mu_{2}=$ rata-rata hasil penilaian juri ke-2

$\mu_{3}=$ rata-rata hasil penilaian juri ke-3

$\mu_{4}=$ rata-rata hasil penilaian juri ke-4

$\mu_{5}=$ rata-rata hasil penilaian juri ke-5

Kemudian untuk mengidentifikasi faktor-faktor lain yang berpengaruh signifikan terhadap hasil penilaian juri atau terhadap kualitas situs web digunakan metode statistik Multiple Linear Regression. Akan dianalisis apakah penilaian juri dipengaruhi oleh level instansi (apakah berada pada level pusat, provinsi, atau kabupaten), prestasi tahun sebelumnya; dan lokasi (Jawa atau Luar Jawa). Persamaan regresi yang akan diuji adalah:

$$
Y=\beta_{0}+\beta_{1} L_{1}+\beta_{2} L_{2}+\beta_{3} A_{1}+\beta_{4} L+c
$$

Keterangan:

$\mathrm{Y}=$ rata-rata nilai juri

$\beta_{0}=$ konstanta

$\beta_{1}=$ koefisien variable dummy-level instansil

$\beta_{2}=$ koefisien variable dummy-level instansi 2

$\beta_{3}=$ koefisien dummy prestasi tahun sebelumnya

$\beta_{4}=$ koefisien dummy lokasi

$\mathrm{L}_{1}=$ dummy level instansi1

$\mathrm{L}_{2}=$ dummy level instansi2

$\mathrm{A}_{1}=$ dummy prestasi tahun sebelumnya

$\mathrm{L}=$ dummy lokasi

Untuk menentukan apakah koefisien-koefisien regresi tersebut mempengaruhi nilai variable dependent $(Y)$ atau tidak; dilakukan uji t-parsial. Hipotesis yang digunakan adalah:

$\mathrm{H}_{0}: \beta_{\mathrm{i}}=0 \quad$ dengan $\mathrm{i}=0,1,2,3,4$

$\mathrm{H}_{1}: \beta_{\mathrm{i}} \neq 0$

Level of significance $(\alpha)$ yang digunakan adalah 0,05 . Jika $P$-value $<\alpha=0,05$ maka tolak $\mathrm{H}_{0}$, tetapi jika $P$-value $\geq \alpha=0,05$ maka terima $\mathrm{H}_{0}$.

\section{HASIL DAN PEMBAHASAN}

Untuk menghitung ANOVA, digunakan perangkat Microsoft Office Excel 2007. Hasil analisis data adalah sebagai berikut: 
Tabel 1. Penilaian Kategori Eselon I - tahun 2008

Anova: Single Factor

SUMMARY

\begin{tabular}{|c|c|c|c|c|}
\hline Groups & Count & Sum & Average & Variance \\
\hline juri1 & 12 & 628.2500 & 52.3542 & 52.2438 \\
\hline juri2 & 12 & 766.7100 & 63.8925 & 153.7289 \\
\hline juri3 & 12 & 793.5500 & 66.1292 & 67.2298 \\
\hline juri4 & 12 & 775.5000 & 64.6250 & 307.0398 \\
\hline juri5 & 12 & 934.5000 & 77.8750 & 60.2670 \\
\hline
\end{tabular}

\begin{tabular}{|c|c|c|c|c|c|c|}
\hline Source of Variation & SS & $d f$ & MS & $F$ & $P$-value & F crit \\
\hline Between Groups & 3939.8621 & 4 & 984.9655 & 7.6889 & 0.0001 & 2.5397 \\
\hline Within Groups & 7045.6020 & 55 & 128.1019 & & & \\
\hline Total & 10985.4641 & 59 & & & & \\
\hline
\end{tabular}

Dari tabel diatas diketahui $F=7,6889 \geq \mathrm{F}$-tabel $=2,5397$ sehingga dapat disimpulkan bahwa H0 ditolak pada $\alpha=0,05$ yang berarti bahwa setidaknya ada 2 juri yang memberikan penilaian berbeda secara signifikan pada pemberian skor situs web Eselon I untuk tahun 2008.

Tabel 2. Penilaian Kategori Eselon I - tahun 2009

Anova: Single Factor

SUMMARY

\begin{tabular}{|c|c|c|c|c|}
\hline Groups & Count & Sum & Average & Variance \\
\hline juri1 & 12 & 752.9893 & 62.7491 & 351.9230 \\
\hline juri2 & 12 & 803.6500 & 66.9708 & 555.0384 \\
\hline juri3 & 12 & 617.0500 & 51.4208 & 393.7957 \\
\hline juri4 & 12 & 828.0400 & 69.0033 & 248.3570 \\
\hline juri5 & 12 & 772.2571 & 64.3548 & 508.0570 \\
\hline
\end{tabular}

\begin{tabular}{|c|c|c|c|c|c|c|}
\hline Source of Variation & SS & $d f$ & $M S$ & $F$ & $P$-value & F crit \\
\hline Between Groups & 2252.7928 & 4 & 563.1982 & 1.3689 & 0.2567 & 2.5397 \\
\hline Within Groups & 22628.8812 & 55 & 411.4342 & & & \\
\hline Total & 24881.6740 & 59 & & & & \\
\hline
\end{tabular}

Dari tabel diatas diketahui bahwa $\mathrm{F}=1,3689<\mathrm{F}$-tabel $=2,5397$ sehingga dapat disimpulkan bahwa $\mathrm{H}_{0}$ diterima pada $\alpha=0,05$ yang berarti bahwa tim juri memberikan penilaian yang tidak berbeda secara signifikan pada saat pemberian skor atau penilaian situs web Eselon I untuk kasus tahun 2009. 
Tabel 3. Penilaian Kategori Eselon I - tahun 2010

Anova: Single Factor

SUMMARY

\begin{tabular}{|c|c|c|c|c|}
\hline Groups & Count & Sum & Average & Variance \\
\hline juri1 & 12 & 901.0000 & 75.0833 & 92.0833 \\
\hline juri2 & 12 & 784.0000 & 65.3333 & 301.5152 \\
\hline juri3 & 12 & 756.0000 & 63.0000 & 494.0000 \\
\hline juri4 & 12 & 869.0000 & 72.4167 & 129.5379 \\
\hline juri5 & 12 & 873.0000 & 72.7500 & 104.0227 \\
\hline
\end{tabular}

ANOVA

\begin{tabular}{|c|c|c|c|c|c|c|}
\hline Source of Variation & SS & $d f$ & MS & $F$ & P-value & $F_{\text {crit }}$ \\
\hline Between Groups & 1315.4333 & 4 & 328.8583 & 1.4666 & 0.2249 & 2.5397 \\
\hline Within Groups & 12332.7500 & 55 & 224.2318 & & & \\
\hline Total & 13648.1833 & 59 & & & & \\
\hline
\end{tabular}

Dari tabel diatas diketahui $\mathrm{F}=1,4666<\mathrm{F}$-tabel $=2,5397$ sehingga dapat disimpulkan bahwa $\mathrm{H}_{0}$ diterima pada $\alpha=0,05$ yang berarti bahwa tim juri memberikan penilaian yang tidak berbeda satu sama lain pada saat pemberian skor untuk berbagai situs web Eselon I pada kasus lomba tahun 2010.

Tabel 4. Penilaian Kategori Provinsi - tahun 2008

\begin{tabular}{|c|c|c|c|c|c|}
\hline \multicolumn{5}{|l|}{$\begin{array}{l}\text { Anova: Single Factor } \\
\text { SUMMARY }\end{array}$} & \\
\hline Groups & Count & Sum & Average & Variance & \\
\hline juri1 & 10 & 633.3400 & 63.3340 & 16.4844 & \\
\hline juri2 & 10 & 639.2500 & 63.9250 & 84.2785 & \\
\hline juri3 & 10 & 714.5000 & 71.4500 & 10.8444 & \\
\hline juri4 & 10 & 774.1500 & 77.4150 & 26.6973 & \\
\hline juri5 & 10 & 791.0000 & 79.1000 & 42.8778 & \\
\hline \multicolumn{6}{|l|}{ ANOVA } \\
\hline Source of Variation & SS & $d f$ & MS & $F$ & $P$-value $F$ crit \\
\hline Between Groups & 2157.7787 & 4 & 539.4447 & 14.8868 & 0.00002 .5787 \\
\hline Within Groups & 1630.6415 & 45 & 36.2365 & & \\
\hline Total & 3788.4202 & 49 & & & \\
\hline
\end{tabular}

Dari tabel diatas diketahui $\mathrm{F}=14,8868 \geq \mathrm{F}$-tabel $=2,5787$ sehingga dapat disimpulkan bahwa $\mathrm{H}_{0}$ ditolak pada $\alpha=0,05$ yang berarti bahwa setidaknya ada 2 juri yang memberikan penilaian yang berbeda secara signifikan pada saat pemberian skor situs web SKPD provinsi lingkup pertanian untuk kasus tahun 2008. 
Tabel 5. Penilaian Kategori Provinsi - tahun 2009

Anova: Single Factor

SUMMARY

\begin{tabular}{|c|c|c|c|c|}
\hline Groups & Count & Sum & Average & Variance \\
\hline juri1 & 10 & 636.4000 & 63.6400 & 308.3538 \\
\hline juri2 & 10 & 693.0000 & 69.3000 & 193.3444 \\
\hline juri3 & 10 & 488.5000 & 48.8500 & 173.3783 \\
\hline juri4 & 10 & 726.0000 & 72.6000 & 86.4889 \\
\hline juri5 & 10 & 693.9286 & 69.3929 & 166.5751 \\
\hline
\end{tabular}

\begin{tabular}{|c|c|c|c|c|c|c|}
\hline Source of Variation & SS & $d f$ & MS & $F$ & P-value & F crit \\
\hline Between Groups & 3579.2301 & 4 & 894.8075 & 4.8204 & 0.0025 & 2.5787 \\
\hline Within Groups & 8353.2650 & 45 & 185.6281 & & & \\
\hline Total & 11932.4951 & 49 & & & & \\
\hline
\end{tabular}

Dari tabel diatas diketahui $\mathrm{F}=4,8204 \geq \mathrm{F}$-tabel 2,5787 sehingga dapat disimpulkan bahwa $\mathrm{H}_{0}$ ditolak pada $\alpha=0,05$ yang berarti bahwa setidaknya ada 2 juri yang memberikan penilaian berbeda secara signifikan pada situs web SKPD provinsi lingkup pertanian pada lomba web tahun 2009.

Tabel 6. Penilaian Kategori Provinsi - tahun 2010

Anova: Single Factor

SUMMARY

\begin{tabular}{|c|c|c|c|c|}
\hline Groups & Count & Sum & Average & Variance \\
\hline juri1 & 10 & 735.0000 & 73.5000 & 23.1667 \\
\hline juri2 & 10 & 641.0000 & 64.1000 & 154.1000 \\
\hline juri3 & 10 & 719.0000 & 71.9000 & 42.9889 \\
\hline juri4 & 10 & 766.0000 & 76.6000 & 15.1556 \\
\hline juri5 & 10 & 653.0000 & 65.3000 & 657.5667 \\
\hline
\end{tabular}

\begin{tabular}{|c|c|c|c|c|c|c|}
\hline Source of Variation & SS & $d f$ & $M S$ & $F$ & $P$-value & $F$ crit \\
\hline Between Groups & 1159.2800 & 4 & 289.8200 & 1.6228 & 0.1850 & 2.5787 \\
\hline Within Groups & 8036.8000 & 45 & 178.5956 & & & \\
\hline Total & 9196.0800 & 49 & & & & \\
\hline
\end{tabular}

Dari tabel diatas diketahui $\mathrm{F}=1,6228<\mathrm{F}$-tabel $=2,5787$ sehingga dapat disimpulkan bahwa $\mathrm{H}_{0}$ diterima pada $\alpha=0,05$ yang berarti bahwa tim juri memberikan penilaian yang tidak berbeda secara signifikan pada penilaian situs web SKPD provinsi lingkup pertanian pada tahun 2010. 
Tabel 7. Penilaian Kategori Kabupaten - tahun 2008

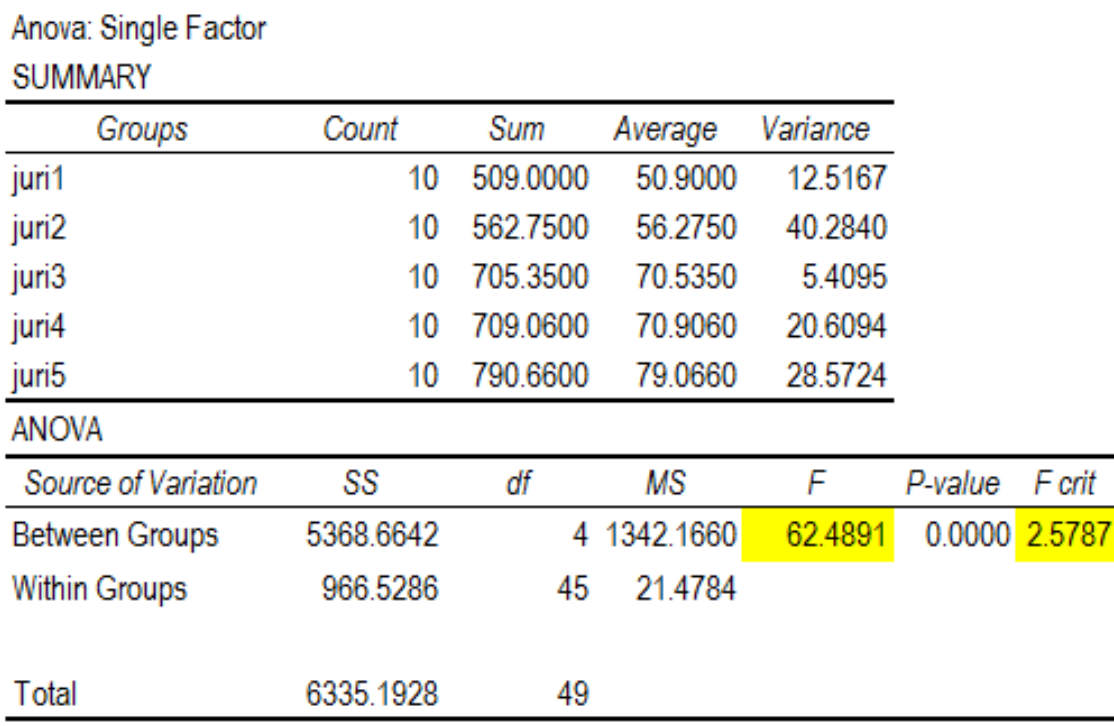

Dari tabel diatas diketahui $\mathrm{F}=62,4891 \geq \mathrm{F}$-tabel $=2,5787$ sehingga dapat disimpulkan bahwa $\mathrm{H}_{0}$ ditolak pada $\alpha=0,05$ yang berarti bahwa setidaknya ada 2 juri yang memberikan penilaian berbeda pada situs web SKPD kabupaten/kota lingkup pertanian pada tahun 2008.

Tabel 8. Penilaian Kategori Kabupaten - tahun 2009

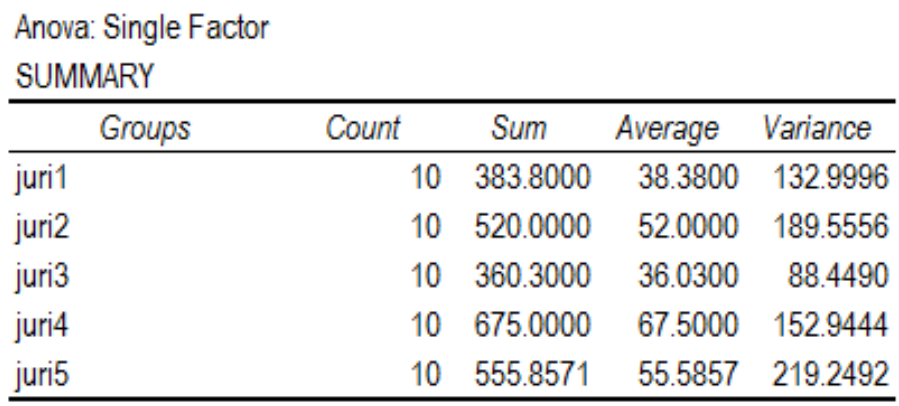

\begin{tabular}{|c|c|c|c|c|c|c|}
\hline Source of Variation & SS & $d f$ & $M S$ & $F$ & P-value & $F_{\text {crit }}$ \\
\hline Between Groups & 6715.8464 & & 41678.9616 & 10.7186 & 0.0000 & 2.5787 \\
\hline Within Groups & 7048.7799 & 45 & $5 \quad 156.6396$ & & & \\
\hline Total & 13764.6263 & 49 & & & & \\
\hline
\end{tabular}

Dari tabel diatas diketahui $\mathrm{F}=10,7186 \geq \mathrm{F}$-tabel 2,5787 sehingga dapat disimpulkan bahwa $\mathrm{H}_{0}$ ditolak pada $\alpha=0,05$ yang berarti bahwa setidaknya ada 2 juri yang memberikan penilaian berbeda secara signifikan pada pemberian skor situs web SKPD kabupaten/kota lingkup pertanian pada lomba web site yang diselenggarakan tahun 2009. 
Tabel 9. Penilaian Kategori Kabupaten - tahun 2010

Anova: Single Factor

SUMMARY

\begin{tabular}{|c|c|c|c|c|}
\hline Groups & Count & Sum & Average & Variance \\
\hline juri1 & 10 & 626.0000 & 62.6000 & 495.6000 \\
\hline juri2 & 10 & 480.0000 & 48.0000 & 379.3333 \\
\hline juri3 & 10 & 566.0000 & 56.6000 & 481.1556 \\
\hline juri4 & 10 & 608.0000 & 60.8000 & 492.8444 \\
\hline juri5 & 10 & 610.0000 & 61.0000 & 514.4444 \\
\hline
\end{tabular}

ANOVA

\begin{tabular}{|c|c|c|c|c|c|c|}
\hline Source of Variation & SS & $d f$ & MS & $F$ & P-value & $F_{\text {crit }}$ \\
\hline Between Groups & 1397.6000 & 4 & 349.4000 & 0.7392 & 0.5702 & 2.5787 \\
\hline Within Groups & 21270.4000 & 45 & 472.6756 & & & \\
\hline Total & 22668.0000 & 49 & & & & \\
\hline
\end{tabular}

Dari tabel diatas diketahui $\mathrm{F}=0,7392<\mathrm{F}$-tabel 2,5787 sehingga dapat disimpulkan bahwa $\mathrm{H}_{0}$ diterima pada $\alpha=0,05$ yang berarti bahwa tim juri memberikan penilaian yang sama pada situs web SKPD kabupaten/kota lingkup pertanian pada tahun 2010. Untuk menentukan persamaan regresi masing-masing tahun penilaian digunakan tabel hasil pengolahan data berikut:

Tabel 10. Penilaian Kategori Tim Juri- tahun 2008

\begin{tabular}{|c|c|c|c|c|c|c|c|c|}
\hline \multicolumn{9}{|l|}{ SUMMARY OUTPUT } \\
\hline \multicolumn{2}{|c|}{ Regression Statistics } & & & & & & & \\
\hline Multiple R & 0.7575 & & & & & & & \\
\hline R Square & 0.5738 & & & & & & & \\
\hline Adjusted R Square & 0.5107 & & & & & & & \\
\hline Standard Error & 4.6408 & & & & & & & \\
\hline Observations & 32 & & & & & & & \\
\hline \multicolumn{9}{|l|}{ ANOVA } \\
\hline & $d f$ & SS & MS & $F$ & Significance $F$ & & & \\
\hline Regression & 4 & 783.0422 & 195.7605 & 9.0895 & 0.0001 & & & \\
\hline Residual & 27 & 581.4995 & 21.5370 & & & & & \\
\hline \multirow[t]{2}{*}{ Total } & 31 & 1364.5416 & & & & & & \\
\hline & Coefficients & Standard Error & $t$ Stat & $P$-value & Lower 95\% & Upper $95 \%$ & Lower $95,0 \%$ & Upper $95,0 \%$ \\
\hline Intercept & 62.5671 & 1.9409 & 32.2365 & 0.0000 & 58.5847 & 66.5494 & 58.5847 & 66.5494 \\
\hline level1 & -0.2612 & 2.1869 & -0.1195 & 0.9058 & -4.7485 & 4.2260 & -4.7485 & 4.2260 \\
\hline level2 & 5.5480 & 2.0871 & 2.6583 & 0.0130 & 1.2657 & 9.8303 & 1.2657 & 9.8303 \\
\hline tigabesar & 9.1161 & 1.9171 & 4.7552 & 0.0001 & 5.1826 & 13.0496 & 5.1826 & 13.0496 \\
\hline lokasi & 0.3901 & 2.1995 & 0.1774 & 0.8605 & -4.1228 & 4.9031 & -4.1228 & 4.9031 \\
\hline
\end{tabular}

Dari tabel diatas diperoleh bahwa hanya $P$-value untuk variabel Intercept, level2, dan dummy tigabesar yang lebih kecil dari $\alpha=0,05$ yang berarti untuk variabel-variabel tersebut signifikan berpengaruh terhadap hskor penilaian. Sehingga persamaan regresi yang digunakan adalah:

$\mathrm{Y}_{2008}=62,567+5,5480$ Level2 $+9,1161$ Tigabesar. 
Tabel 11. Penilaian Kategori Tim Juri- tahun 2009

\begin{tabular}{|c|c|c|c|c|c|c|c|c|}
\hline \multicolumn{2}{|c|}{ SUMMARY OUTPUT } & & & & & & & \\
\hline \multicolumn{2}{|c|}{ Regression Statistics } & & & & & & & \\
\hline Multiple R & 0.6990 & & & & & & & \\
\hline R Square & 0.4886 & & & & & & & \\
\hline Adjusted R Square & 0.4128 & & & & & & & \\
\hline Standard Error & 11.9719 & & & & & & & \\
\hline Observations & 32 & & & & & & & \\
\hline \multicolumn{9}{|l|}{ ANOVA } \\
\hline & $d f$ & SS & MS & $F$ & Significance $F$ & & & \\
\hline Regression & 4 & 3697.1401 & 924.2850 & 6.4488 & 0.0009 & & & \\
\hline Residual & 27 & 3869.7983 & 143.3259 & & & & & \\
\hline \multirow[t]{2}{*}{ Total } & 31 & 7566.9384 & & & & & & \\
\hline & Coefficients & Standard Error & $t$ Stat & P-value & Lower $95 \%$ & Upper $95 \%$ & Lower $95,0 \%$ & Upper $95,0 \%$ \\
\hline Intercept & 42.2703 & 5.4745 & 7.7213 & 0.0000 & 31.0375 & 53.5031 & 31.0375 & 53.5031 \\
\hline level1 & 12.9717 & 5.4591 & 2.3762 & 0.0248 & 1.7706 & 24.1728 & 1.7706 & 24.1728 \\
\hline level2 & 15.7915 & 5.6435 & 2.7982 & 0.0094 & 4.2121 & 27.3710 & 4.2121 & 27.3710 \\
\hline tigabesar & 18.1481 & 4.9677 & 3.6532 & 0.0011 & 7.9552 & 28.3410 & 7.9552 & 28.3410 \\
\hline lokasi & 3.1218 & 5.9475 & 0.5249 & 0.6039 & -9.0813 & 15.3250 & -9.0813 & 15.3250 \\
\hline
\end{tabular}

Dari tabel diatas diperoleh bahwa variabel Lokasi memiliki $P$-value $>\alpha=0,05$ yang berarti untuk variabel ini terima $\mathrm{H}_{0}$ (variable tersebut tidak berpengaruh signifikan terhadap skor) dan variabel lainnya tolak $\mathrm{H}_{0}$. (berpengaruh signifikan terhadapvariabel Skor). Persamaan regresi estimatenya adalah:

$\mathrm{Y}_{2009}=42,2703+12,9717$ level $1+15,7915$ level $2+18,1481$ tigabesar.

Tabel 12. Penilaian Kategori Tim Juri- tahun 2010

\begin{tabular}{|c|c|c|c|c|c|c|c|c|}
\hline \multicolumn{9}{|c|}{ SUMMARY OUTPUT } \\
\hline \multicolumn{2}{|c|}{ Regression Statistics } & & & & & & & \\
\hline Multiple R & 0.6307 & & & & & & & \\
\hline R Square & 0.3978 & & & & & & & \\
\hline Adjusted R Square & 0.3086 & & & & & & & \\
\hline Standard Error & 12.4224 & & & & & & & \\
\hline Observations & 32 & & & & & & & \\
\hline \multicolumn{9}{|l|}{ ANOVA } \\
\hline & $d f$ & SS & MS & $F$ & Significance $F$ & & & \\
\hline Regression & 4 & 2752.5410 & 688.1353 & 4.4593 & 0.0068 & & & \\
\hline Residual & 27 & 4166.5077 & 154.3151 & & & & & \\
\hline \multirow[t]{2}{*}{ Total } & 31 & 6919.0488 & & & & & & \\
\hline & Coefficients & Standard Error & $t$ Stat & $P$-value & Lower 95\% & Upper 95\% & Lower $95,0 \%$ & Upper $95,0 \%$ \\
\hline Intercept & 55.0484 & 5.8204 & 9.4579 & 0.0000 & 43.1060 & 66.9908 & 43.1060 & 66.9908 \\
\hline level1 & 13.7172 & 5.6537 & 2.4262 & 0.0222 & 2.1168 & 25.3176 & 2.1168 & 25.3176 \\
\hline level2 & 11.1917 & 6.0801 & 1.8407 & 0.0767 & -1.2835 & 23.6670 & -1.2835 & 23.6670 \\
\hline tigabesar & 16.6869 & 4.9842 & 3.3480 & 0.0024 & 6.4603 & 26.9136 & 6.4603 & 26.9136 \\
\hline lokasi & -3.2207 & 6.1766 & -0.5214 & 0.6063 & -15.8940 & 9.4526 & -15.8940 & 9.4526 \\
\hline
\end{tabular}

Dari tabel diatas diperoleh bahwa hanya $P$-value untuk variabel Intercept, dummy variabel level1, dan dummy tigabesar yang lebih kecil dari $\alpha=0,05$ yang berarti untuk variabel-variabel tersebut tolak $\mathrm{H}_{0}$. Sehingga persamaan regresi estimatenya adalah:

$\mathrm{Y}_{2010}=55,0484+13,7172$ Dummy Level1 $+16,6889$ Dummy Tiga-besar. 


\section{PENUTUP}

Dari hasil uji statistik diketahui bahwa penilaian juri untuk kategori Eselon I lingkup Kementerian Pertanian tahun 2009 dan 2010 cenderung menilai lebih baik dibandingkan tahun 2008 karena hasil penilaian secara rata-rata antar juri tidak berbeda secara signifikan.

Penilaian juri untuk kategori SKPD provinsi lingkup pertanian yang berbeda secara signifikan hanya pada tahun 2008 dan 2009. Demikian juga penilaian juri untuk kategori SKPD kabupaten/kota lingkup pertanian. Dari hasil regresi pada tahun 2008, variabel level instansi pusat dan variabel lokasi (Jawa atau luar Jawa) tidak berpengaruh signifikan terhadap rata-rata hasil penilaian oleh tim juri. Yang berpengaruh secara signifikan justru level provinsi dan posisi tahun sebelumnya (3 besar). Untuk hasil regresi tahun 2009, variabel dummy level instansi dan posisi tahun sebelumnya juga berpengaruh signifikan terhadap hasil skor penilaian tim juri. Pada tahun 2010, yang berpengaruh signifikan terhadap hasil/skor penilaian oleh Tim juri adalah level instansi pusat dan posisi tahun sebelumnya dengan koefisien masing-masing 13,7172 dan 16,6869.

\section{DAFTAR PUSTAKA}

Pusat Sumberdaya Geologi. (2003). Pengembangan dan Implementasi e-Government.

Presiden Republik Indonesia. (2003). Instruksi Presiden Nomor 3 Tahun 2003 tentang Kebijakan dan Strategi Nasional Pengembangan e-Government. Jakarta: Sekretaris Kabinet RI.

Pusat Data dan Informasi, Kementrian Pertanian. (2010) Panduan Penyelenggaraan Lomba Situs Web 2010

Kementerian Komunikasi dan Informasi. (2003a). Panduan Penyelenggaraan Situs Web Pemerintah Daerah.

Kementerian Komunikasi dan Informasi. (2003b). Acuan Rating Situs Web Pemerintah. 